6. Baccus-Taylor G, Frederick P, Akingbala J. (2016) Studies on pomerac (syzygium malaccense) candied fruit slices. ISHS Acta Horticulturae 806: International Symposium on Underutilized Plants for Food Security, Nutrition, Income and Sustainable Development. 293-300.

7. N.Z. Raykhel', N.V. Alekseyeva, G.Z. Dzhayshibekov, ZH.N. Kaypova (2017). Sposoby proizvodstva tsukatov. Mezhdunarodnyy zhurnal prikladnykh i fundamental'nykh issledovaniy № 2-2. 168-171.

8. V. Atamanyuk, I. Huzova, Z. Gnativ (2017). Study of diffusion processes in pumpkin particles during candied fruits production. Food Science and Technology. 11(4). $21-28$.

9. E. Neau, O. Hermandez-Garduza. (2009). The Soave, Twu and Boston-Mathias alpha functions in cubic equations of state. P. II Modeling of thermodynamic properties of pure compounds . Fluid phase equilibria. V. 276. 156-164.

Отримано в редакцію 04.05 .2018

Прийнято до друку 26.06.2018
Received 04.05.2018

Approved 26.06.2018

\title{
МОДЕЛЮВАННЯ РУХУ БУЛЬБАШОК СТИСНЕНОГО ПОВІТРЯ У АПАРАТІ 3 ПНЕВМАТИЧНИМ ПЕРЕМІШУВАННЯМ
}

\author{
Данилюк О. М. аспірант, Атаманюк В. М. д.т.н., професор, Гумницький Я. М. д.т.н., професор \\ Національний університет «Львівська політехніка», м. Львів
}

\begin{abstract}
Анотація. Проведено огляд і аналіз літературних джерел, які відображають основні результати та напрямки досліджень процесу розчинення під час пневматичного перемішування. Вони показують, які проблемні напрями науки потребують детальніших досліджень. Обгрунтовано вибір методу розчинення під час пневматичного перемішування розчину. Розглянуто переваги даного методу. До переваг використання пневматичного перемішування належить рівномірний та інтенсивний масообмін між твердою фазою та рідиною. Використання стисненого повітря для перемішування спрощує внутрішню конструкцію апарату. Завдяки изьому також виключається забруднення розчину продуктами корозї чи ерозї перемішуючих пристроїв. Описано процес утворення окремої бульбашки у рідкому середовищі з певної глибини під час повільного витікання повітря у рідину із отвору з гострими кромками.

Експериментально досліджено процес руху бульбашки стисненого повітря у водному розчині бензойної кислоти в апараті для розчинення під час пневматичного перемімування. Описано процес утворення бульбашок в умовах квазістатичного режиму диспергування стисненим повітрям розчину. Визначено відривний розмір бульбашок повітря з отворів барботеру. Розраховані швидкість спливання бульбашок повітря в апараті та частота їх утворення з отворів барботеру. Розраховано фіктивні швидкості руху бульбашок стисненого повітря в апараті за різних витрат повітря. Наведено результати розрахунків дисипачії енергї̈ в апараті для розчинення бензойної кислоти. Визначені параметри руху бульбашки стисненого повітря узагальнені у вигляді таблиці та графіка. Визначено оптимальні значення витрати повітря та час, за яких доцільно здійснювати процес розчинення під час пневматичного перемішування.
\end{abstract}

Ключові слова: рух бульбашок, розчинення, пневматичне перемішування, енергія, барботер.

\section{SIMULATION OF THE MOVEMENT OF COMPRESSED AIR BUBBLES IN THE APPARATUS WITH PNEUMATIC MIXING}

\author{
Danyliuk O. M. postgraduate student; Atamanuk V. M. Doctor of Technical Sciences, \\ Gumnitsky J. M. Doctor of Technical Sciences \\ National University "Lviv Polytechnic", Lviv, Ukraine
}

\begin{abstract}
This article reviews and analyzes literary sources, which reflect the main results and directions of research of the dissolution process during pneumatic mixing. They show which problem areas of science require more detailed research. The choice of the method of dissolution during the pneumatic mixing of the solution is substantiated.. The advantages of this method are considered. The advantages of using a pneumatic mixing system include the uniform and intensive mass transfer between the solid phase and the liquid. The use of compressed air for mixing simplifies the internal design of the machine. This also eliminates the pollution of the solution by products of corrosion or erosion of mixing devices. The process of formation of a separate bubble in a liquid medium from a certain depth during the slow flow of air into a liquid from a hole with sharp edges is described.

The process of bubble movement of compressed air in an aqueous solution of benzoic acid, in the apparatus for dissolution during pneumatic mixing is experimentally investigated. The process of formation of bubbles is described in the conditions of the quasi-static regime of dispersion with compressed air of a solution.
\end{abstract}




\section{Одеська національна академія харчових технологій МОДЕЛЮВАННЯ КОМБІНОВАНИХ ПРОЦЕСІВ ПЕРЕНОСУ. ОПТИМІЗАЦІЯ ОБЛАДНАННЯ І СИСТЕМ}

Determined tear-off size of air bubbles from the bubbler apertures. The velocity of air bubbles in the apparatus is calculated and the frequency of their formation from the bubbler apertures. The fictitious velocities of bubbles of compressed air in the apparatus for different air flows are calculated. The calculations results of dissipation of energy in the apparatus for dissolution of benzoic acid are presented. The specified parameters of the bubble movement of compressed air are summarized in the form of a table and a graph. The optimal values of air flow and the time during which it is expedient to carry out the dissolution process during pneumatic mixing are determined.

Key words: bubble movement, dissolution, pneumatic mixing, energy, bubbler.

Вступ. Процес розчинення належить до одного із найбільш поширених масообмінних процесів. Проведені дослідження належать, в основному, до питань харчової, хімічної та фармацевтичної промисловостей. Розчинення твердих речовин у промисловості реалізується різними методами: в апараті 3 механічним або пневматичним перемішуванням, в апаратах із псевдозрідженим шаром зернистого матеріалу, перемішування струменем рідини або повітря, у шнекових апаратах та апаратах з рухомим та нерухомим шаром твердої фази [1].

Особливої уваги заслуговують перемішуючі пристрої з підведенням енергії стисненим газом. Одним із шляхів підвищення надійності технічних об'єктів є спрощення їх конструкції. Максимального спрощення конструкції можна досягти лише у випадку, коли безпосередньо носій кінетичної енергії буде наділений функціями виконавчого органу. На даний час апарати із пневматичним перемішуванням не набули широкого використання, проте, вони характеризуються рядом переваг, порівняно із механічними мішалками. У апаратах з пневматичним перемішуванням спрощена внутрішня конструкція, оскільки у них відсутні перемішуючі пристрої, які піддаються впливу механічної та хімічної ерозій. Продукти ерозії та корозії перемішуючих пристроїв додатково забруднюють цільовий продукт розчинення. До переваг використання пневматичного перемішування відноситься також рівномірний та інтенсивний масообмін між твердою фазою та рідиною. Однією із найважливіших характеристик процесу перемішування $\epsilon$ енергія, що вводиться в апарат для здійснення процесу. Тому, дослідження умов формування бульбашок, закономірностей їх руху в апараті, розрахунок оптимальної енергії, яка необхідна для розчинення бензойної кислоти під час пневматичного перемішування розчину, є актуальними завданнями, які потребують подальшого дослідження.

Аналіз останніх досліджень та публікацій. Дослідження роботи апаратів 3 пневматичним перемішуванням безпосередньо пов’язане із дослідженням руху бульбашок стисненого газу у середовищі, що перемішується. Згідно із даними досліджень [2], процес виходу стиснутого повітря через отвори кільцевого напірного трубопроводу супроводжується формуванням струменю, який у процесі руху подрібнюється на окремі бульбашки різного об’єму, що піднімаються у висхідному напрямку. Дослідження бульбашкового процесу, як початкового, в установці для розчинення під час пневматичного перемішування дає змогу сформувати достовірну базу для подальшого теоретичного дослідження та моделювання структури і режиму руху, що формується всередині апарату, та є основою для дослідження динаміки газорідинних сумішей.

У квазістатичному режимі над отвором періодично утворюються бульбашки однакового розміру, що спливають $з$ однією і тією ж швидкістю на однаковій відстані один від одного. Збільшення швидкості газового потоку приводить до зростання частоти утворення газових бульбашок. Їх розміри і швидкість спливання залишаються незмінними, зменшується лише відстань між ними. Подальше зростання швидкості газового потоку приводить до такого режиму утворення бульбашок, коли вони, стикаючись, рухаються ланцюжком або у струменевому режимі.

Авторами [3-4] встановлено, що на бульбашки газу, які спливають у рідині, діють підйомна сила, викликана градієнтом тиску в напрямку руху бульбашки, сила опору рідини, що оточує бульбашку, та сила поверхневого натягу. Дані дослідження описують умови піднімання бульбашки в рідині у вертикальній площині. У [5] наведені результати вимірювання руху повітряної бульбашки у пульсуючій рідині для процесу коливальної флотації. Встановлено залежність абсолютних та відносних швидкостей розростання бульбашок від параметрів пульсації рідини. У роботі [6] проведений комплекс експериментальних та теоретичних досліджень, який дозволив дослідити вплив ряду параметрів (вхідний діаметр, кут нахилу твірної та висота конічного корпусу забірного пристрою; глибина добування та довжина транспортуючого трубопроводу; тиск подачі повітря; діаметр та кут встановлення сопел) на продуктивність пневматичного забірного пристрою для добування сапропелевих сумішей. Також розроблено математичну модель руху повітряної бульбашки у в'язкій рідині [7], яка дозволяє обгрунтувати раціональні межі кута нахилу твірної та висоти конічного корпусу забірного пристрою. Дослідженню розчинення одинарних частинок та розчинення у стаціонарному шарі приділено чимало уваги різними дослідниками, наприклад, у роботах [8]. У роботах $[9,10]$ розглянуто процес фізичного розчинення полідисперної суміші бензойної кислоти в потоці газу та рідини, а також на основі теорії ізотропної турбулентності визначено теоретичний коефіцієнт масовіддачі. 


\section{Одеська національна академія харчових технологій МОДЕЛЮВАННЯ КОМБІНОВАНИХ ПРОЦЕСІВ ПЕРЕНОСУ. ОПТИМІЗАЦІЯ ОБЛАДНАННЯ І СИСТЕМ}

Експериментальні дослідження та обговорення результатів. Аналіз характеристик руху бульбашок стисненого повітря у рідкому середовищі проводили на лабораторній установці, схема і принцип роботи якої представлені у [11]. Дослідження проводили в умовах квазістатичного режиму, який спостерігається за невеликих швидкостей руху повітря, коли можна не враховувати інерцію взаємодіючих середовищ. У цьому режимі об'єм бульбашки в момент відриву не залежить від витрати стисненого повітря, у той же час частота їх утворення зростає пропорційно до витрати повітря. Вважаємо, що повітряний потік складається із окремих бульбашок кулястої форми. Розглянемо процес утворення окремої бульбашки з відривним розміром $\delta$ і об'ємом $\mathrm{V}$, у рідкому середовищі з глибини Н під час повільного витікання

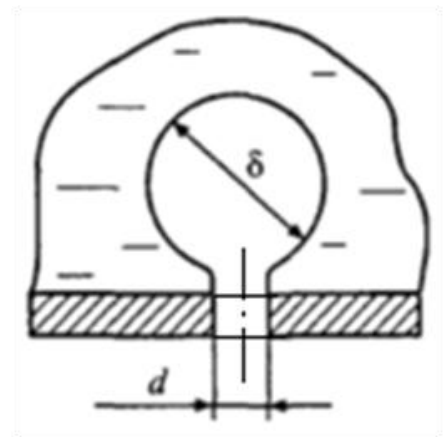

Рис.1. Схема відриву бульбашки. повітря у рідину із отвору з гострими кромками (рис.1).

Для квазістатичного процесу умови відриву бульбашки можна представити як рівновагу сил поверхневого натягу, що утримують бульбашку по периметру отвору, і рівнодійної сил ваги повітря та Архімеда, що відривають бульбашку.

Умову рівноваги запишемо у вигляді:

$$
\frac{\pi \cdot \delta^{3}}{6} \cdot\left(\rho_{1}-\rho_{2}\right) \cdot g=\pi \cdot d \cdot \sigma,
$$

звідки, після введення коригуючого коефіцієнта $\eta_{\sigma}$, що враховує спрощення моделі і відхилення форми бульбашки від сферичної в момент відриву, отримаємо:

$$
\delta=\sqrt[3]{\eta_{\sigma} \cdot \frac{6 \cdot d \cdot \sigma}{g \cdot\left(\rho_{1}-\rho_{2}\right)}}
$$

де $\delta$ - відривний діаметр бульбашки, м; d- діаметр отвору, м; $\rho_{1}, \rho_{2}-$ густина рідини та повітря, кг/м ${ }^{3}$; $\sigma=0,0732 \mathrm{H} / \mathrm{M}-$ поверхневий натяг води за температури $16^{\circ} \mathrm{C}$.

Величина корелюючого коефіцієнта $\eta_{\sigma}$ знаходиться у межах 0,6-1,0 і для газів $\eta_{\sigma} \approx 0,89$ [12].

Відповідно до формули Бернуллі, тиск повітря в бульбашці Р становить:

$$
\mathrm{P}=\mathrm{p}_{\mathrm{a}}+\rho_{1} \cdot \mathrm{g} \cdot \mathrm{H}+\frac{\rho_{2} \cdot \omega^{2}}{2}
$$

де $\mathrm{p}_{\mathrm{a}}$ - атмосферний тиск, Па; $\omega$ - швидкість руху бульбашки, м/с.

Останнім членом рівняння (2) можна знехтувати, оскільки у момент відриву $\omega=0$. Тоді, рівняння запишеться у вигляді:

$$
\mathrm{P}=\mathrm{p}_{\mathrm{a}}+\rho_{1} \cdot \mathrm{g} \cdot \mathrm{H}
$$

Температура стисненого повітря у дослідженнях, яке формує бульбашку, має значення $\mathrm{t} \approx 16{ }^{\circ} \mathrm{C}$ ( Т $\approx 289$ К). Густина повітря за тиску $\mathrm{P}=98,1$ кПа, і даній температурі $\rho_{2}=1,16$ кг $/ \mathrm{m}^{3}$. $10^{-3} \mathrm{M}$

Враховуючи рівняння (1) - (3), відривний розмір бульбашки повітря становитиме: $\delta=3,4$.

Залежно від об’ємної витрати повітря, частота відриву бульбашок від кромки отвору за одиницю часу, буде:

$$
\mathrm{n}=\frac{6 \cdot \mathrm{Q}}{\mathrm{z} \cdot \pi^{3} \cdot \delta^{3}}, 1 / \mathrm{c}
$$

де Q- об'ємна витрата повітря, м³/c; z= 560- кількість отворів перфорованої перегородки барботера у експериментальній установці.

Позначимо через $\omega_{\text {c }}$ середню швидкість спливання бульбашки. Для визначення швидкості спливання бульбашки використаємо рівняння за умови $\rho_{1}>>\rho_{2}$, яке наведено у [13]:

$$
\omega_{\mathrm{c}}=\sqrt{\frac{4 \cdot \delta \cdot \mathrm{g}}{3 \cdot \mathrm{C}}}
$$

де С- коефіцієнт опору середовища.

Для визначення коефіцієнта опору середовища $\mathrm{C}$ згідно з критеріями Вебера We $>1$ і Рейнольдса $\operatorname{Re}>600$ можна використати залежність Хармонті, що справедлива у області критерія Бонда Во $<13$ :

де

$$
\begin{array}{r}
\mathrm{C}=0,568 \cdot \sqrt{\mathrm{Bo}}, \\
\text { Во }=\frac{\mathrm{g} \cdot \delta^{2} \cdot\left(\rho_{1}-\rho_{2}\right)}{\sigma}
\end{array}
$$

Для умов проведення експерименту число Бонда $\mathrm{Bo}=1,57$; а коефіцієнт $\mathrm{C}=0,71$.

Із залежності (5) швидкість спливання бульбашки становить: $\omega_{\mathrm{c}}=0,23 \mathrm{M} / \mathrm{c}$.

Тоді, критерій Рейнольдса $\operatorname{Re}=\frac{\omega_{c} \cdot \rho_{1} \cdot \delta}{\mu}=711 ;$ критерій Вебера $\mathrm{We}=\frac{\omega^{2} \cdot \rho_{1} \cdot \delta}{\sigma}=1,8$. Тобто, умова використання залежності Хармонті виконується. 
Енергія введеного газу передається рідині та зумовлює ії турбулентні переміщення. Ця енергія від великих масштабів турбулентності переходить до малих масштабів та у кінцевому результаті дисипується у даному об'ємі розчину.

Результати розрахунків дисипації енергії, яка вводиться у апарат для розчинення бензойної кислоти під час пневматичного перемішування в умовах квазістатичного руху бульбашок повітря наведені у таблиці 1.

Таблиця 1

Результати розрахунку дисипації енергії в об'ємі апарату

\begin{tabular}{|c|c|c|c|c|}
\hline $\begin{array}{c}\text { Об'ємна ви- } \\
\text { трата газу } \\
\mathrm{Q}^{-1} 0^{-5}, \mathrm{~m}^{3} / \mathrm{c}\end{array}$ & $\begin{array}{c}\text { Час дос- } \\
\text { ліду } \tau \bullet 10^{-} \\
2, \mathrm{c}\end{array}$ & $\begin{array}{c}\text { Швидкість } \\
\text { витікання } \omega, \\
\mathrm{m} / \mathrm{c}\end{array}$ & $\begin{array}{c}\text { Фіктична } \\
\text { швидкість } \\
\omega_{0}, \mathrm{M} / \mathrm{c}\end{array}$ & $\begin{array}{c}\text { Питома енергія } \\
\text { дисипації } \varepsilon_{\mathrm{o}}, \\
\mathrm{BT} / \mathrm{\kappa} \Gamma\end{array}$ \\
\hline 67 & 78 & 1,51 & 0,04 & 0,40 \\
\hline 89 & 72 & 2,02 & 0,05 & 0,51 \\
\hline 111 & 66 & 2,53 & 0,06 & 0,62 \\
\hline 133 & 57 & 3,03 & 0,07 & 0,74 \\
\hline 156 & 51 & 3,55 & 0,08 & 0,86 \\
\hline
\end{tabular}

Дисипацію енергії визначаємо через потужність $\mathrm{N}_{\text {п }}$, яка вводиться в апарат з газовою фазою і дорівнює кінетичній та потенціальній енергії повітря:

$$
\mathrm{N}_{\text {пा }}=\left(\mathrm{p}_{\mathrm{a}}+\rho_{1} \cdot \mathrm{g} \cdot \mathrm{H}+\frac{\rho_{2} \cdot \omega_{0}^{2}}{2}\right) \cdot \mathrm{Q}
$$

Оскільки $\mathrm{p}>\rho_{1} \mathrm{gH}$, то знехтуємо зміною густини повітря. Тоді, потужність, яка виходить 3 апарату разом із повітрям:

$$
\mathrm{N}_{\mathrm{K}}=\left(\mathrm{p}_{\mathrm{a}}+\frac{\mathrm{\rho}_{2} \cdot \omega_{0}^{2}}{2}\right) \cdot \mathrm{Q}
$$

Дисипацію енергії в апараті визначимо із рівняння:

$$
\varepsilon_{0}=\frac{\mathrm{N}_{n}-\mathrm{N}_{\mathrm{k}}}{\mathrm{H} \cdot \rho_{1} \cdot \frac{\pi \cdot \mathrm{d}^{2}}{4}}=\omega_{0} \cdot \mathrm{g}+\frac{\rho_{2} \cdot \omega_{0}}{2 \cdot \rho_{1} \cdot \mathrm{H}} \cdot\left(\omega^{2}-\omega_{\mathrm{c}}^{2}\right),
$$

де $\omega_{0}=\frac{4 \cdot \mathrm{Q}}{\pi \cdot \mathrm{d}^{2}}-$ фіктивна швидкість газу, м/с; d - діаметр апарату, м. $\omega_{\mathrm{c}}-$ швидкість спливання бульбашки, м/с; $\omega$ - швидкість витікання повітря крізь отвори перфорованої перегородки, м/с.

Фіктивна швидкість руху повітря, яке подається крізь отвори барботера в рідке середовище апарату, буде рівна:

де S- площа перерізу отвору, м $^{2}$

$$
\omega_{0}=\frac{\mathrm{Q}}{\mathrm{z} \cdot \mathrm{S}},
$$

Для визначення оптимального значення витрати повітря, за якої доцільно здійснювати процес розчинення під час пневматичного перемішування, на основі таблиці 1, побудовано графік залежності розподілу енергії в апараті від витрати стиснутого повітря і тривалості процесу.

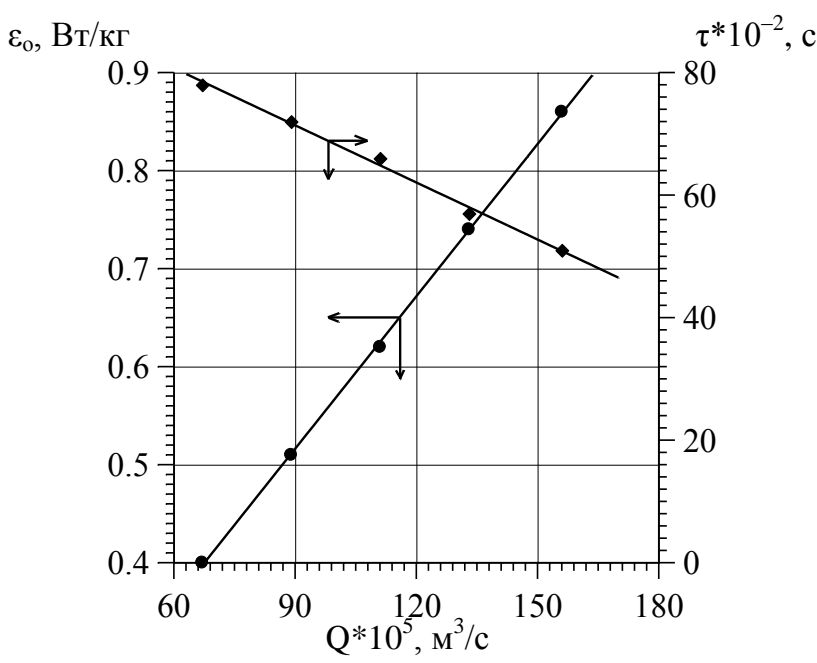

Рис.2. Залежність розподілу енергії в апараті від витрати стиснутого повітря і тривалості процесу до досягнення концентрації насичення. - - тривалість процесу, с; •- зміна енергії в апараті, Вт/кг.

Аналіз графічної залежності, наведеної на рис.2 дає змогу встановити оптимальну витрату стиснутого повітря, за якої доцільно проводити процес розчинення під час пневматичного перемішування роз- 


\section{Одеська начіональна академія харчових технологій \\ МОДЕЛЮВАННЯ КОМБІНОВАНИХ ПРОЦЕСІВ ПЕРЕНОСУ. \\ ОПТИМІЗАЦІЯ ОБЛАДНАННЯ І СИСТЕМ}

чину. Такою витратою у заданому гідродинамічному режимі $\epsilon 136 \cdot 10^{-5} \mathrm{~m}^{3} / \mathrm{c}$, що відповідає введеній енергії у кількості $0,75 \mathrm{Bт} / к г$.

\section{Висновки}

1. Експериментально досліджено процес руху бульбашки стисненого повітря у водному розчині, в апараті для розчинення під час пневматичного перемішування.

2. Описано процес утворення бульбашок в умовах квазістатичного режиму диспергування стисненого повітря в розчин.

3. Визначено відривний розмір бульбашок повітря з отворів барботеру та розраховано їх швидкість.

4. Визначено розподіл енергії в апараті для розчинення під час пневматичного перемішування рідини в межах квазістатичного режиму руху за різних витрат повітря.

5. Знайдено оптимальну витрату стиснутого повітря для здійснення процесу розчинення бензойної кислоти під час пневматичного перемішування.

\section{Література}

1. Бабенко Ю. Влияние нестационарных эффектов на скорость растворения одиночной частицы / Ю. Бабенко, Е. Иванов // Теор. основы хим. Технологии. - 2013. - Т. 47, № 6. - С. 624-629.

2. Цизь І. Дослідження руху повітряного потоку у в'язких рідинах / І. Цизь, С. Хомич, Р. Трохимчук // Сільськогосподарські машини: Зб. наук. статей. Вип. 29-30. Луцьк: Ред.вид., відділ ЛНТУ. - 2014. - С. 153-162.

3. Островский Г. Прикладная механика неоднородных сред / Г. Островский // М.: Наука. - 2000. - 359 с.

4. Черновол М. Конструювання, виробництво та експлуатація сільськогосподарських машин / М. Чорновол, А. Бойко, В. Гамалій та інші // Науково-технічний збірник. Кіровоград: КНТУ. -2012. - 254 с.

5. Krasnov G. Air bubble movement in pulsating liquid / G. Krasnov // Journal of Mining Science. Vol. 42, No. 5. - 2006. - P. 500505 .

6. Tsiz' I. Experimental research of working process of pneumatic intake device for sapropel extraction / I. Tsiz', S. Homich // INMATEH - Agricultural Engineering. Vol. 40, No. 2. - 2013. - p. 67-72.

7. Хомич С. Моделювання процесу руху бульбашки повітря у середовищі сапропелю / С. Хомич // Конструювання, виробництво та експлуатація сільськогосподарських машин. Кіровоград: КНТУ. - 2012. - Вип. 42, Ч.2. - С.147-152.

8. Симак Д. Нестаціонарний процес розчинення шару зернистого матеріалу / Д. Симак, О. Люта // Хімія, технологія речовин та їх застосування. Л.: Видавництво Нац. ун-ту “Львів. Політехніка”, №812. - 2015. - С.308-312.

9. Symak D. Investigation of physical dissolution of benzoic acid polydisperse mixture / D. Symak, J. Gumnitsky, V. Atamaniuk, O. Nagurskyy // Chemistry and Chemical Technology. Volume 11, Issue 4. - 2017.- Pp. 469-474.

10. Symak, D. Analysis of dissolution kinetics based on the local isotropic turbulence theory / D. Symak, V. Atamanyuk, Y. Gumnytskyy // Chemistry and Chemical Technology. Volume 9, Issue 4. - 2015.- Pp. 493-496.

11. Данилюк О. Дослідження закономірностей процесу розчинення полідисперсних частинок бензойної кислоти під час пневматичного перемішування / О. Данилюк, В. Атаманюк, Я. Гумницький, М. Бачик // Інтегровані технології та енергозбереження. B.4. - 2017. - C.36-40.

12. Kuznetsov V.V. Heat and Mass Transfer with Phase Change and Chemical Reactions in Microscale / V.V. Kuznetsov // Proc. Int. Heat Transfer Conf. IHTC14. - Washington DC: ASME, 2010. - Keynote IHTC14-22570.

13. Островський Г. Прикладная механика неоднородних сред / Г. Островський // СПб, Наука. - 2000. - 359 с.

\section{References:}

1. Babenko YU., Ivanov Ye. (2013) Vliyaniye nestatsionarnykh effektov na skorost' rastvoreniya odinochnoy chastitsy. Teor. osnovy khim. Tekhnologii. 47(6), 624-629.

2. Tsyz' I., Khomych S., Trokhymchuk R. (2014) Doslidzhennya rukhu povitryanoho potoku u v"yazkykh ridynakh. Sil's'kohospodars'ki mashyny: Zb. nauk. statey. Luts'k: Red.vyd., viddil LNTU. 29(30). 153-162.

3. Ostrovskiy G. (2000) Prikladnaya mekhanika neodnorodnykh sred. Moscow. Nauka. 359.

4. M. Chornovol, A. Boyko, V. Hamaliy (2012) Konstruyuvannya, vyrobnytstvo ta ekspluatatsiya sil's'kohospodars'kykh mashyn. Naukovo-tekhnichnyy zbirnyk. Kirovohrad: KNTU. 254

5. Krasnov G. (2006) Air bubble movement in pulsating liquid. Journal of Mining Science. 42(5), 500-505.

6. Tsiz' I., Homich S. (2013) Experimental research of working process of pneumatic intake device for sapropel extraction. INMATEH - Agricultural Engineering. 40(2), 67-72.

7. Khomych S. (2012) Modelyuvannya protsesu rukhu bul'bashky povitrya u seredovyshchi sapropelyu. Konstruyuvannya, vyrobnytstvo ta ekspluatatsiya sil's'kohospodars'kykh mashyn. Kirovohrad: KNTU. 42(2), 147-152.

8. Symak D., Lyuta O. (2015) Nestatsionarnyy protses rozchynennya sharu zernystoho materialu. Khimiya, tekhnolohiya rechovyn ta yikh zastosuvannya. L.: Vydavnytstvo Nats. un-tu "L'viv. Politekhnika", 812. 308-312.

9. Symak D., Gumnitsky J., Atamaniuk V., Nagurskyy O. (2017) Investigation of physical dissolution of benzoic acid polydisperse mixture. Chemistry and Chemical Technology. 11(4), 469-474.

10. Symak D., Atamanyuk V., Gumnytskyy Y. (2015) Analysis of dissolution kinetics based on the local isotropic turbulence theory. Chemistry and Chemical Technology. 9(4), 493-496.

11. Danylyuk O., Atamanyuk V., Humnyts'kyy YA., Bachyk M. (2017) Doslidzhennya zakonomirnostey protsesu rozchynennya polidyspersnykh chastynok benzoynoyi kysloty pid chas pnevmatychnoho peremishuvannya. Intehrovani tekhnolohiyi ta enerhozberezhennya. 4. 36-40.

12. Kuznetsov V.V. (2010) Heat and Mass Transfer with Phase Change and Chemical Reactions in Microscale. Proc. Int. Heat Transfer Conf. IHTC14. - Washington DC: ASME, - Keynote IHTC14-22570.

13. Ostrovs'kiy G. (2000) Prikladnaya mekhanika neodnorodnykh sred. SPb, Nauka. 359.

Отримано в редакцію 14.05.2018

Прийнято до друку 30.06.2018
Received 14.05.2018

Approved 30.06.2018 